\title{
Psychometric responsiveness of the health- related quality of life questionnaire (HeartQoL-P) in the Iranian post-myocardial infarction patients
}

\author{
F. Ranjandish, H. Mahmoodi and A. Shaghaghi (1)
}

\begin{abstract}
Background: Cardiovascular diseases (CVD) as a most frequent and costly NCDs account for about 17.3 million annual deaths worldwide. About $80 \%$ of these deaths are taking place in low and middle income countries (LMIC). The survivors may experience severe disabling consequences with extensive impacts on their quality of life. The HeartQoL is a relatively new scale to measure health-related quality of life in CVD patients and was validated for use in other languages. Main aim of the present study was to validate the HeartQoL for Persian speaking populations.
\end{abstract}

Design and methods: In this cross-sectional study the participants were 557 admitted patients with acute myocardial infarction (AMI) across three specialized hospitals in Tabriz, North West of Iran from Sep 2014 to Feb 2015. Translation back-translation procedures were applied to prepare the Persian version of the HeartQol (HeartQoL-P) and the content validity of the scale was evaluated by an expert panel of 10 academic staff. Construct validity was assessed by exploratory and confirmatory factor analyses. The internal consistency was assessed based on the numeric value of Cronbach's alpha and sensitivity of the measure according to the ceiling and floor effect's values.

Results: The two-factor structure of the HeartQoL-P was supported by the confirmatory factor analysis' outputs and good internal consistency measures (total score $a=0.94$ ) (physical subscale (10 items) $a=0.95$ ) and emotional subscale (4items) $a=0.80)$ ). No ceiling and floor effects were observed for the overall HeartQol-P's score.

Conclusion: The findings supported the HeartQoL-P usability as a valid instrument in studies on the Iranian or other Persian speaking patients.

Keywords: Myocardial ischemia, Acute coronary syndrome, Coronary thrombosis, Angina pectoris, Life quality, Persian

\section{Introduction}

Non-communicable diseases (NCDs) are the dominant cause-specific component of death, disability and other socio-economic burden in low and middle income countries (LMIC). [1] Cardiovascular diseases (CVD) as one of the most frequent and costly NCD are the leading cause of death that account for about 17.3 million annual deaths worldwide and this toll is estimated to raise to more than 23.6 million by 2030. [2] More than $80 \%$ of all CVD related deaths are taking place in LMIC. [2] The overall global CVD mortality increased almost $41 \%$

\footnotetext{
* Correspondence: shaghaghir@tbzmed.ac.ir; ar.shaghaghi@gmail.com Department of Health Education \& Promotion, Faculty of Health, Tabriz University of Medical Sciences, Tabriz, Iran
}

during 1990-2013 [3] and the burden will continue to grow in the coming decades if an effective intervening measure will not be scheduled.

Acute myocardial infarction is one of the main causes of death in Iran $[4,5]$ that imposed significant human and non-human costs on the country's productivity with exacerbated effect on the rural and deprived areas (e.g. adjusted incidence rate of 152.5 per 100,000 population in a relatively deprived province compared to the average countrywide rate of 73.3 per 100,000 population as reported for 2012). [5] Therefore; CVD related mortality or its disabling consequences is one of the greatest challenges for the Iranian National Health System (INHS) and whole country since it was projected that the

(c) The Author(s). 2019 Open Access This article is distributed under the terms of the Creative Commons Attribution 4.0 International License (http://creativecommons.org/licenses/by/4.0/), which permits unrestricted use, distribution, and reproduction in any medium, provided you give appropriate credit to the original author(s) and the source, provide a link to the Creative Commons license, and indicate if changes were made. The Creative Commons Public Domain Dedication waiver (http://creativecommons.org/publicdomain/zero/1.0/) applies to the data made available in this article, unless otherwise stated. 
estimated 847,309 CVD related DALYs (Disability-Adjusted Life Years) in the country's adult population aged $\geq 30$ years old in 2005 to increase more than two fold and reach $1,728,836$ by 2025 . [6]

Those patients who survive from an acute heart attack may experience severe disabling consequences with extensive impacts on their quality of life for the remaining years. [7] This means that the survivors and their family members' perceived health, comfort and level of happiness may be diminished in the context of the culture and value systems in which they live and their hopes and dreams ruin due to the disease related hassles in front of reaching their goals, and meeting expectations or standards of living. [8]

Due to usage of a range of condition-specific (MI, heart failure, angina) questionnaires in different studies and considering their inherent inaccuracy and lacking of the required specificity for general usage, cross comparison of the studies' result on quality of life of the patients with ischemic heart disease (IHD) is absurd. [9] The HeartQoL tool developed by Oldridge $\mathrm{N}$ et al. [10] is a relatively new hybrid scale to measure health-related quality of life in patients with IHD and studied on patients across 22 countries and 15 languages. [9] The scale development was based on the three well known condition-specific instruments to measure patients' quality of life i.e.: (1) MacNew Heart Disease HRQoL (developed for patients with MI), (2) Minnesota Living with Heart Failure, and (3) Seattle Angina Questionnaire [9]. Advantage of this new tool for quality of life measurement in patients with IHD is its easy applicability in clinic and out of clinic settings, relatively short time required for its completion and its efficiency as a core single instrument to be used for other patients with angina, MI and heart failure. $[10,11]$ The instrument was validated for use in other languages and different types of patients [12, 13] but not validated for use in Persian speaking population. Application of disease-specific instrument to measure quality of life could add sensitivity in differentiating patients' conditions based upon the imposed burden by an explicit disease. Main aim of the present study therefore, was to validate the HeartQol-P for Iranian post-myocardial infarction patients. .

\section{Materials and methods}

\section{Study participants}

In this cross-sectional study, a convenience sample of discharged patients who had been admitted in the coronary care units with diagnosis of acute myocardial infarction in the previous 4 weeks to 6 months period were recruited from only specialized inpatients CVD wards of three main hospitals in Tabriz the capital city of East Azarbaijan province, North West of Iran. All of the included hospitals are affiliated to the Iranian National
Health System (INHS). The targeted patients had been discharged from the hospitals and were approached in their homes.

The patients discharge lists were used to select the stable and eligible patients (aged $\geq 18$ years, diagnosed with AMI, not having any serious cognitive disorder). Thus; 557 patients (410 men and 147 women) after explanation of the study objectives were contacted and invited to participate in the study. The sample size was decided based on the optimum number of participants (20) determined per item in the scale (14 items). Exploratory Factor Analysis (EFA) was performed on a random split half sample of the study data to examine factor structure of the scale's items and Confirmatory Factor Analysis (CFA) in the holdout sample to validate the identified factor structure.

Data about the general characteristics of the patients who agreed to participate in the study were collected through phone contact, email and face to face questioning. The study aims and objectives were explained orally in face to face meetings (66) or through telephone call (491). Data collection through telephone call or email was applied only for those patients who were not willing to attend the interview place at the hospitals or stated their preference to answer the study questions by telephone or email.

The informed consent form was sent to the patients' postal address in the printed format upon their request and they were advised to return the completed form in the case of their willingness to participate. Exclusion criteria was unfamiliarity with Persian language (common in limited sub-samples of the country population due to having a different mother language e.g. Turkic, Kurdish, Gilaki, Mazandarani and Balochi) or having a severe disabling condition such as body paralysis which could considerably affect people's life. Data about socio-demographic properties including age, sex, educational level and also history of background illnesses including type two diabetes and hypertension and also patients' lifestyle habits i.e. smoking and daily physical activity level (before and after AMI) were collected for all study respondents between September 2014 and February 2015.

\section{Instrument (HeartQol)}

The HeartQol questionnaire is a relatively new tool for examining health-related quality of life amongst patients with IHD [11] and was validated across 22 countries. [9, 12-16] The HeartQoL's items are listed after an introductory phrase i.e. "We would like to know how your heart problem has bothered you and how you have been feeling during the last 4 weeks" and consist 14 questions in the physical and emotional subscales with answer options ranging from 0 to 3 (poor to better health related quality of life). The original scale's reliability based on the reported Cronbach alpha was $\geq 0.80$. [17] 
Forward-backward translation procedures were applied to prepare the Persian version of the HeartQol. $[18,19]$ The forward translation was carried out by two fluent speakers of Persian language with good knowledge of English. The back translation process was done by two professional translators and a cardiologist checked the final version for its conformity with the original text. Some modifications were made in the Persian translated version after comparing the English back-translated version with the original scale. To assure face and content validities a panel of 10 health professionals were asked to assess and give their comments on the translated instrument. Lucidity of the wording and easy understandability of the scale's items were also pilot tested on the 30 study participants and minor corrections or amendments were made consequently. To add efficiency of the data collection procedure the pilot phase collected data were included in the main study. [20]

\section{Data analysis}

Mean and standard deviation of the HeartQol-P's scores in line with absolute and relative frequencies of the baseline variables were calculated. The ceiling and floor effects (CFEs) were appraised by examining the percentage of scores at the boundaries of the score range (e.g. 0 and 100). [21, 22] The CFEs are a matter of concern if more than $15 \%$ of respondents achieve the lowest or highest possible score, respectively. Cronbach's alpha and Interclass Correlation Coefficient (ICC) were computed for evaluating internal consistency and reliability of the scale and values above 0.7 were deemed to be acceptable. [23]

Exploratory Factor Analysis (EFA) was used to examine any underlying (or latent) relationships between the variables. EFA was carried out by Principal Axis Factoring (PAF) extraction method utilizing Varimax Rotation with Kaiser Normalization. The scree plot procedure was used for deciding on the number of factors to be extracted. [24]

KMO (Kaiser-Meyer Olkin) measure of sampling adequacy, Bartlett's test of sphericity and total explained variance were used for the evaluation of model sufficiency. High values of KMO (more than 0.7) generally indicate that a factor analysis may be suitable for a data set. Bartlett's test of sphericity speculates the hypothesis that whether a correlation matrix is an identity matrix (i.e. variables are unrelated and therefore unsuitable for structure detection). A $P$ value less than 0.05 was considered statistically significant. Factor loading values equal to 0.6 and above were interpreted as representing a good convergent validity or correlation between the items of the identified factors. [25] Confirmatory Factor Analysis (CFA) output was examined to assess construct validity of the adapted instrument. The CFA fit indices and their considered acceptable values were Chi-squared/ $\mathrm{df}<5.00$, Root Mean Square Error of Approximation (RMSEA) < 0.08, Comparative Fit Index (CFI), Goodness of Fit Index (GFI) and Adjusted Goodness of Fit Index $(A G F I)>0.90$. [26] The IBM SPSS (version 19) and AMOS (version 18) software was used for data analysis.

\section{Results \\ Content validity \\ Socio-demographic characteristics}

All of the invited patients (557 including 410 (73.6\%) men and 147 (26.4\%) women) agreed to participate and completed the study questionnaire (response rate 100\%).The respondents' age range was from 29 years to 92 years ( mean $=62.7$ years; $\mathrm{SD}=12.3$ years). Other characteristics of the study participants were indicated in Table 1 . The HeartQoL-P total mean score for all patients was 19.43 $( \pm 9.86)$ and a statically significant difference was observed between two sexes $(p<0.001)$ (males' mean score $=18.36$, SD: 9.92 and females' mean score $=22.43$, SD: 9.05). No ceiling and floor effects were observed for the overall HeartQol-P's score. The content validity ratio (CVR) and content validity index (CVI) represented acceptable ranges i.e. 0.62 and 0.81 , respectively. [26]

\section{Reliability}

The estimated Cronbach's alpha for the translated version of the scale was 0.94 which is in the vicinity of acceptable range for internal consistency measure (above 0.7). The reliability coefficients for the two sub scales of the HeartQol-P were also in the acceptable range i.e. the emotional subscale ( 4 items, $\alpha=0.80$ ) and the physical subscale (10 items, $\alpha=0.95$ ) (Table 2).

\section{Construct validity}

\section{Exploratory factor analysis}

The Exploratory Factor Analysis (EFA) was conducted using data from about half of the study sample (i.e. 275 patients) as recommended when the sample size allows. $[27,28]$ The output statistics in terms of KMO (KaiserMeyer-Olkin) measure of sampling adequacy (0.93) and Bartlett's test of sphericity $(X(91)=7345.1, P<0.001)$ represented EFA usefulness for the data analysis. The total variance explained by the scale's two factors was $71.93 \%$ and the Scree plot supported the unidimensionality of the HeartQol-P questionnaire (Fig. 1).

The factor loadings of the 14 items in the HeartQol-P were presented in Table 3 . The identified factors were emotional factor consisting items 9-12 and also physical factor including items $1-8$ and 13-14.

\section{Confirmatory factor analyses (CFA)}

The results of the CFA for two-factor model indicated a satisfactory fit $\left(\mathrm{X}^{2} / \mathrm{df}=2.93<5\right.$, RMSR (Root Mean Square Residual $)=0.052$, RMSEA $(90 \%$ CI $)=0.084(0.071$; 
Table 1 The participants' characteristics in the psychometric study of the health-related quality of life questionnaire (HeartQoL-P) in the Iranian post-myocardial infarction patients $(n=557)$

\begin{tabular}{|c|c|}
\hline Variables & Frequencies (\%) \\
\hline \multicolumn{2}{|l|}{ Sex } \\
\hline Male & $410(73.6)$ \\
\hline Female & $147(26.4)$ \\
\hline \multicolumn{2}{|l|}{ Age range } \\
\hline$<50$ & $95(17.0)$ \\
\hline $50-70$ & $304(54.6)$ \\
\hline$>70$ & $158(28.4)$ \\
\hline \multicolumn{2}{|l|}{ Education $(n=545)$} \\
\hline Illiterate & $241(44.2)$ \\
\hline Primary \& high school certificate & $205(37.6)$ \\
\hline Diploma \& college degree & $83(15.3)$ \\
\hline BSC \& higher & $16(2.9)$ \\
\hline \multicolumn{2}{|l|}{ AMl time } \\
\hline $0-3$ months & $248(44.5)$ \\
\hline $4-6$ months & $309(55.5)$ \\
\hline \multicolumn{2}{|l|}{ Smoking } \\
\hline Before AMI & $259(46.5)$ \\
\hline After AMl & $70(12.6)$ \\
\hline \multicolumn{2}{|l|}{ Adequate physical activities } \\
\hline \multicolumn{2}{|l|}{ Before AMI } \\
\hline Daily & $78(14.0)$ \\
\hline Occasionally & $248(44.6)$ \\
\hline Never & $230(41.4)$ \\
\hline \multicolumn{2}{|l|}{ After AMl } \\
\hline Daily & $78(14.0)$ \\
\hline Occasionally & 187 (33.6) \\
\hline Never & $291(52.2)$ \\
\hline \multicolumn{2}{|l|}{ Other co-morbidities } \\
\hline T2 diabetes & $183(32.9)$ \\
\hline Hypertension & $420(75.4)$ \\
\hline
\end{tabular}

$0.097), \mathrm{CFI}=0.963, \mathrm{PGFI}=0.613$, and AGFI $=0.86)$. The item-to-factors correlations and also the observed correlations among the two factors (Fig. 2) were statistically significant $(P<0.05)$.

\section{Discussion}

The results of this study showed that the translated HeartQol-P questionnaire is a valid and reliable tool for measuring quality of life in patient survived from acute myocardial infarction in the Iranian population.

No floor or ceiling effects (i.e. more than $15 \%$ of the study participants produce the maximum or minimum possible scores on a scale) were observed for the total and subscales' scores of the HeartQoL-P questionnaire which is consistent with the psychometric properties of the main questionnaire. [17] Content validity of the HeartQol-P questionnaire was approved based on both qualitative (i.e. inspection of comments from the expert panel members) and quantitative analysis (i.e. scrutiny of the level of agreement among expert panel members) by examining values of the content validity ratio (CVR) and content validity index (CVI) that represent simplicity, relevancy and clarity of the scale's items. [10] The translated HeartQol-P questionnaire indicated good internal consistency (the Cronbach alpha for the total score and each subscale was between 0.80 and 0.95). The finding in an agreement with other reported reliability measures in previous studies that ranged from 0.80 to 0.91 [17] and Cronbach alpha $(\alpha) \geq 0.90$, test-retest reliability index (ICC) $\geq 0.90$ in the study of Kristensen et al. on patients with atrial fibrillation [29], Cronbach $\alpha$ values between 0.88 and 0.92 on the global scale and each subscale in the study of Oldridge et al. ([13] or Cronbach's alpha $>0.90$ and test-retest reliability index of $>0.90$ in the study of Zangger et al. [16]

Construct validity of the HeartQol-P was evaluated using EFA and CFA. The results revealed that a two factor model consisting of physical and emotional component was a good fit to the data which is in line with findings of other psychometric studies of the HeartQol. [13, 15-17]

Despite an acceptable representation of the validity and reliability measures, the study findings warrant to be interpreted by caution. Non-random selection of the study participants and their socio-cultural distinct properties could prohibit generelizability of the study findings

Table 2 Scale properties of the HeartQol items in the psychometric responsiveness of the health-related quality of life questionnaire (HeartQoL) in the Iranian post-myocardial infarction patients $(n=275)$

\begin{tabular}{lllllll}
\hline Scale & Number of Items & Mean & SD & Floor-effect (\%) & Ceiling-effect (\%) & Cronbach's a \\
\hline Emotional & 4 & 1.23 & 0.75 & 5.0 & 3.4 & 0.80 \\
Physical & 10 & 1.44 & 0.79 & 1.1 & 2.5 & 0.95 \\
Total & 14 & 1.38 & 0.70 & 0.2 & 1.1 & 0.94 \\
\hline
\end{tabular}




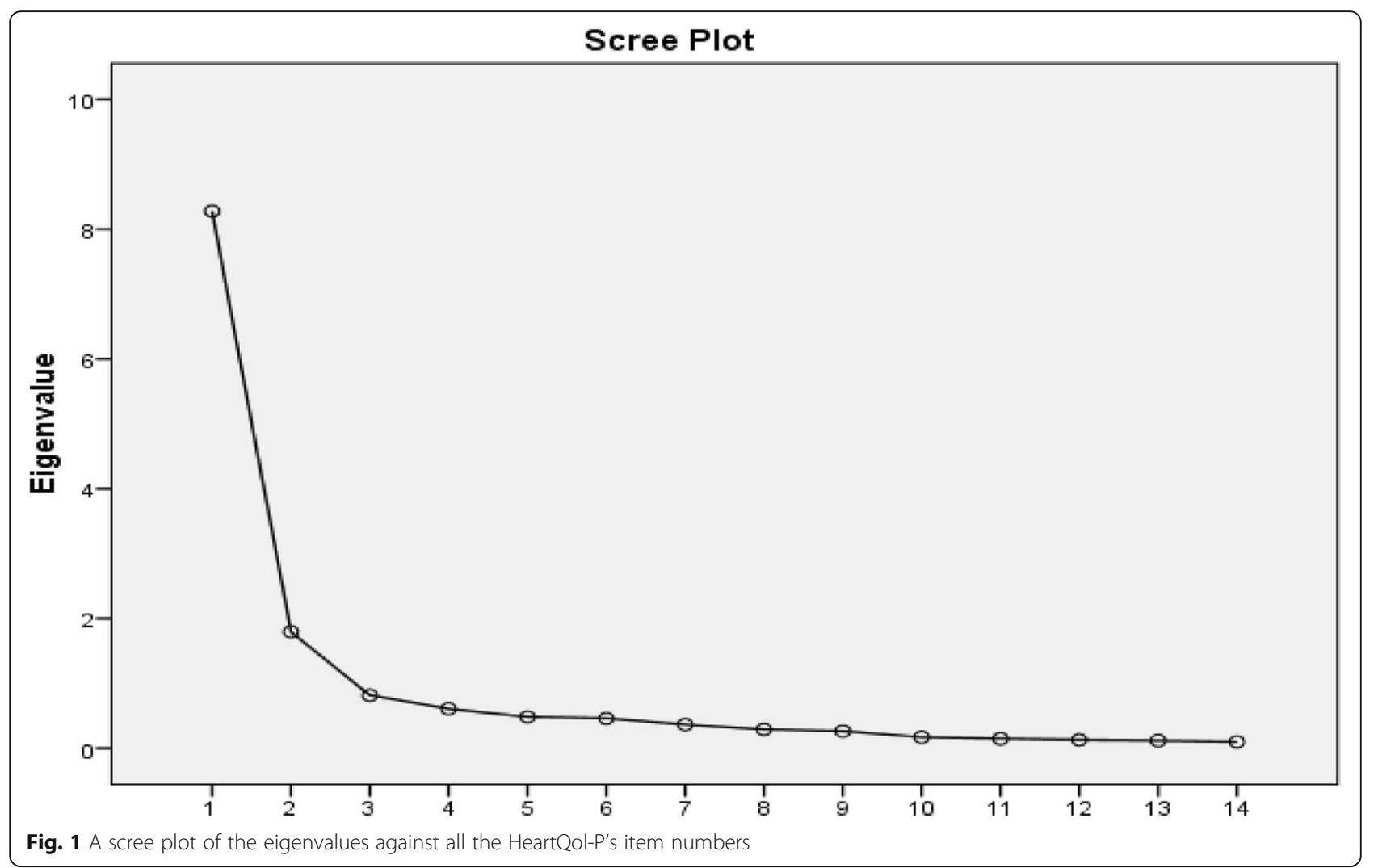

to other different populations. The age range and gender of the participants might also have effect on their total and subscale's scores. Time from the AMI event to the study participation date ranged from 4 weeks to 6 months (mean $=3.71$ months and $\mathrm{SD}=1.63)$. We believe that different time period after myocardial infarction or clinical severity of the AMI could cause different outcomes and quality of life. Therefore; subgroup analysis based on the different times frames after AMI is recommended for future studies. However; considering main

Table 3 Explanatory Factor Analysis* pattern of matrix loadings for 14 items in the psychometric responsiveness of the translated Health-Related Quality of Life questionnaire (HeartQoL-P) in the Iranian post-myocardial infarction patients $(n=275)$

\begin{tabular}{llll}
\hline Items & Questions & Factor 1 & Factor 2 \\
\hline Q4 & Fast walking for more than 100 m & $\mathbf{0 . 9 0 6}$ & 0.160 \\
Q3 & Going up stairs or a hill / Going down stairs or a hill without taking a break & $\mathbf{0 . 8 9 7}$ & $\mathbf{0 . 8 9 7}$ \\
Q13 & Exercise intolerance & $\mathbf{0 . 8 7 9}$ \\
Q2 & Gardening, vacuuming, carrying groceries & $\mathbf{0 . 8 7 1}$ \\
Q14 & Working only at home or yard environment & $\mathbf{0 . 8 4 3}$ \\
Q5 & Lifting or moving heavy objects & $\mathbf{0 . 8 3 2}$ \\
Q1 & Walking on the ground at home & $\mathbf{0 . 7 8 2}$ \\
Q7 & Physical restriction & $\mathbf{0 . 7 2 0}$ \\
Q6 & Shortness of breath & $\mathbf{0 . 6 0 4}$ \\
Q8 & Tiredness, fatigue, lack of energy & 0.201 \\
Q10 & Feeling depressed & 0.363 \\
Q12 & Feeling anxious & -0.052 \\
Q11 & Feeling hopeless & 0.205 \\
Q9 & Feeling under tension or restlessness & 0.356 & $\mathbf{0 . 2 6 7}$ \\
\hline
\end{tabular}

*Explanatory Factor Analysis (EFA) using (Principal Axis Factor) PAF extraction method and varimax rotation with Kaser normalization/bold numbers indicate the items related to the corresponding factor//Factor 1 (physical), Factor2 (emotional) 


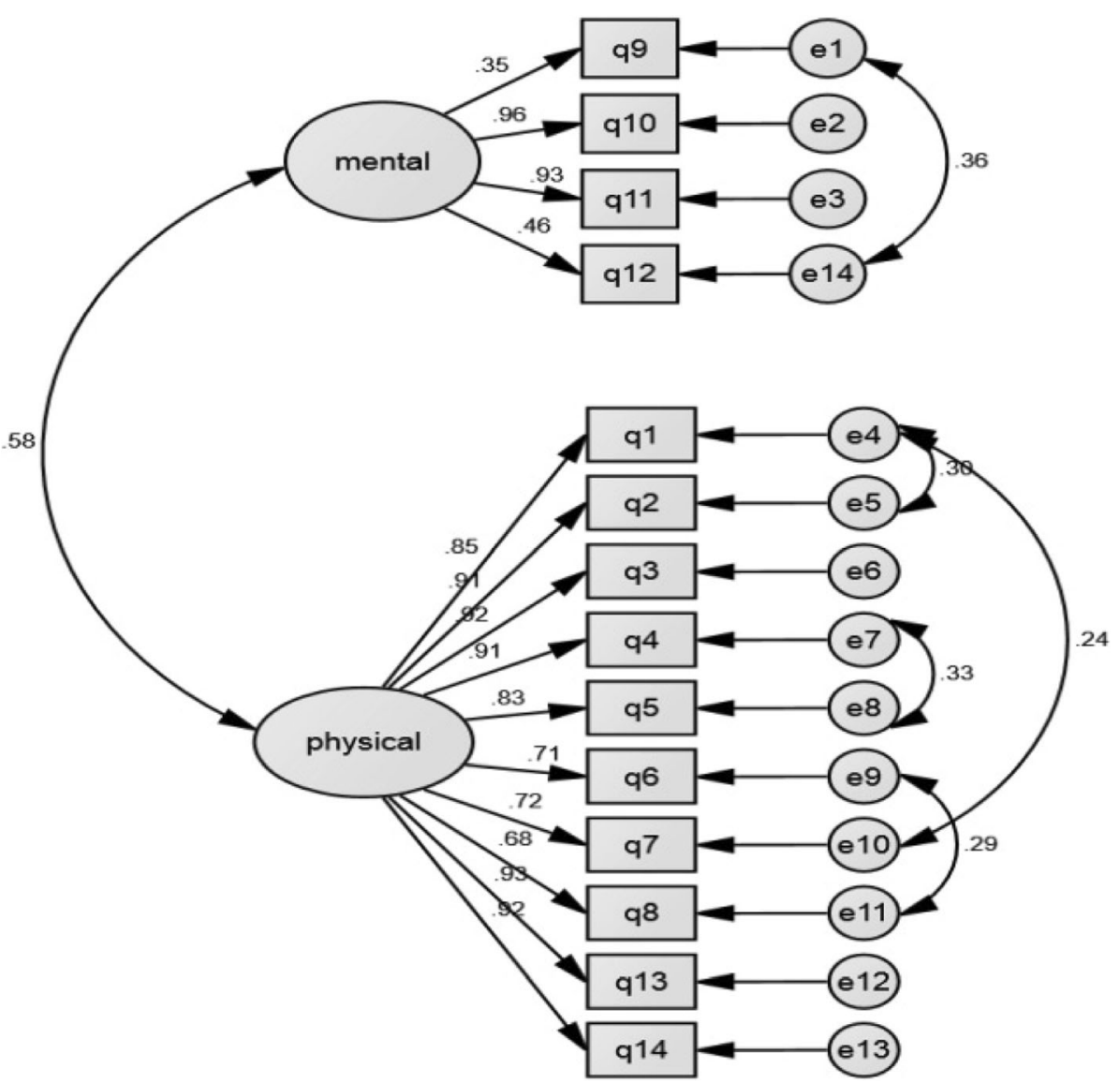

Fig. 2 Path diagram of the HeartQol-P's loading items on the two-factor confirmatory-exploratory model

objective of this study (assessment of the psychometric properties of the translated scale) the wide time frame could not be a source of major concern in the interpretation of the study results. Different data collection methods applied in the study i.e. telephone call, face to face interview, email could also pose serious threat to the validity of the study findings. Application of a consistent data collection method is recommended for future studies on the psychometric assessment of the scale. Further research is required therefore; to appraise age adjusted and cross-cultural adaptability of the translated version in different sub-groups of the Iranian population and other Persian speaking countries and also to examine its reliability over a longer time period.

\section{Conclusion}

Perceived quality of life in patient survived from acute myocardial infarction could pose crucial impact on their recovery and sustaining physical and mental wellbeing. Therefore, measurement of the ascertained quality of life in these patients might have a high priority for accurate health care interventions. Findings of this study were indicated that the HeartQol-P questionnaire has the acceptable properties for its use in prediction of quality of life amongst Persian speaking populations. Therefore, its application as a disease sensitive instrument to measure AMI patients' quality of life in Iran and other Persian speaking countries is recommended however; cross cultural validity of the scale must be investigated in the countries' sub-groups of populations in future studies.

\section{Abbreviations}

AFGI: Adjusted goodness of fit index; AMl: Acute myocardial infarction; CFA: Confirmatory factor analysis; CVD: Cardiovascular disease; CVI: Content validity index; CVR: Content validity ratio; EFA: Exploratory factor analysis; GFI: Goodness of fit index; HeartQoL: Health-related quality of life questionnaire; ICC: Interclass correlation coefficient; INHS: Iranian national health system; KMO: Kaiser-Meyer Olkin; PAF: Principal axis factoring; RMSEA: Root mean square error of approximation; RSMR: Root-mean-square residuals; SD: Standard deviation

\section{Acknowledgements}

The authors would like to thank all the patients for their kind participation in the study.

\section{Funding}

This study was founded by the Tabriz University of Medical Sciences (Ref number: $5 / 53 / 2665)$. 


\section{Availability of data and materials}

The datasets generated in the current study or analysis results are available from the corresponding author on reasonable request.

\section{Authors' contributions}

AS and FR conceived the original idea and designed the study. FR collected the study data. AS, FR and HM contributed to statistical analysis and interpreted the findings. FR drafted the manuscript with inputs from all authors. AS commented on the early drafts of the manuscript and provided critical feed backs several times and took the lead in preparation of the final draft. All authors read and approved the final manuscript.

\section{Ethics approval and consent to participate}

Approval for the study was obtained from the Board of Trustees on Medical Ethics within the Tabriz University of Medical Science (approval number: 5/4/ 4084-1394-04-18). The study attendees were assured about anonymity of the study data and the possibility of withdrawing from the study whenever and for any reason they had. Written informed consent of those participants who indicated their willingness to attend the study was obtained.

\section{Consent for publication}

Not applicable.

\section{Competing interests}

All authors declare that they have no competing interest.

\section{Publisher's Note}

Springer Nature remains neutral with regard to jurisdictional claims in published maps and institutional affiliations.

Received: 11 October 2017 Accepted: 20 December 2018

Published online: 14 January 2019

\section{References}

1. Lim GB. Public health: global burden of cardiovascular disease. Nat Rev Cardiol. 2013;10:59

2. American Heart Association/American Stroke Association. Heart Disease and Stroke Statistics - At-a-Glance, https://www.heart.org/idc/groups/ahamahpublic/@wcm/@sop/@smd/documents/downloadable/ucm_470704.pdf (2014, accessed 10 March 2017).

3. O'Rourke K, VanderZanden A, Shepard D, et al. Cardiovascular disease worldwide, 1990-2013. JAMA. 2015;314(18):1905.

4. Talaei M, Sarrafzadegan N, Sadeghi M, et al. Incidence of cardiovascular diseases in an Iranian population: the Isfahan cohort study. Arch Iran Med. 2013;16(3):138-44.

5. Ahmadi A, Soori H, Mehrabi Y, et al. Incidence of acute myocardial infarction in Islamic Republic of Iran: a study using national registry data in 2012. East Mediterr Health J. 2015;21(1):5-12.

6. Sadeghi M, Haghdoost AA, Bahrampour A, et al. Modeling the burden of cardiovascular diseases in Iran from 2005 to 2025: the impact of demographic changes. Iran J Public Health. 2017:46(4):506-16.

7. Dyer MT, Goldsmith KA, Sharples LS, et al. A review of health utilities using the EQ-5D in studies of cardiovascular disease. Health Qual Life Outcomes. 2010;8:13.

8. Skevington SM, Lotfy M, O'Connell KA. The World Health Organization's WHOQOL-BREF quality of life assessment: psychometric properties and results of the international field trial. A report from the WHOQOL group. Qual Life Res. 2004:13(2):299-310.

9. Lee WL, Chinna K, Bulgiba A, et al. Test-retest reliability of HeartQoL and its comparability to the MacNew heart disease health-related quality of life questionnaire. Qual Life Res. 2016;25(2):351-7. https://doi.org/10.1007/ s11136-015-1097-1.

10. Oldridge N, Höfer S, McGee H, et al. The HeartQoL: part I. development of a new core health-related quality of life questionnaire for patients with ischemic heart disease. Eur J Prev Cardiol. 2014;21(1):90-7.

11. Oldridge N. Heartqol questionnaire: a new patient-reported outcome in cardiology. European Health Psychologist. 2014;16(S):379.

12. Pogosova NV, Boycharov $\mathbb{H}$, Sokolova OY, et al. [The new European questionnaire for assessment of Quality of Life of Patients with Ischemic Heart Disease: HeartQoL]. Kardiologiia 2016 (8):66-72. [Article in Russian].
13. Oldridge $\mathrm{N}$, Cho C, Thomas R, et al. Validation of the English version of the HeartQoL health-related quality of life questionnaire in patients with coronary heart disease. J Cardiopulm Rehabil Prev. 2018;38(2):92-9. https:// europepmc.org/abstract/med/28671935.

14. De Smedt D, Clays E, Höfer S, et al. The use of HeartQoL in patients with coronary heart disease: association with risk factors and European reference values. The EUROASPIRE IV study of the European Society of Cardiology. Eur J Prev Cardiol. 2016;23(11):1174-86. https://doi.org/10.1177/ 2047487316631400.

15. Buys R, Goessler KF. The HeartQoL questionnaire is valid for use in implantable cardioverter defibrillator recipients. What does this mean for clinical practice? Eur J Prev Cardiol. 2018;25(2):139-41. https://doi.org/10. 1177/2047487317743047

16. Zangger G, Zwisler AD, Kikkenborg Berg S, et al. Psychometric properties of HeartQoL, a core heart disease-specific health-related quality of life questionnaire, in Danish implantable cardioverter defibrillator recipients. Eur J Prev Cardiol. 2018;25(2):142-9. https://doi.org/10.1177/2047487317733074.

17. Oldridge N, Höfer S, McGee H, et al. The HeartQoL: part II. Validation of a new core health-related quality of life questionnaire for patients with ischemic heart disease. Eur J Prev Cardiol. 2014;21(1):98-106.

18. Guillemin F, Bombardier C, Beaton D. Cross-cultural adaptation of healthrelated quality of life measures: literature review and proposed guidelines. J Clin Epidemiol. 1993;46:1417-32.

19. Beaton DE, Bombardier C, Guillemin F, et al. Guidelines for the process of cross-cultural adaptation of self-report measures. Spine. 2000;25:3186-91.

20. Thabane L, Ma J, Chu R, et al. A tutorial on pilot studies: the what, why and how. BMC Med Res Methodol. 2010;10:1. https://doi.org/10.1186/1471-2288-10-1.

21. Terwee $C B$, Bot SD, de Boer MR, et al. Quality criteria were proposed for measurement properties of health status questionnaires. J Clin Epidemiol. 2007:60(1):34-42.

22. Huang IC, Frangakis C, Atkinson MJ, et al. Addressing ceiling effects in health status measures: a comparison of techniques applied to measures for people with HIV disease. Health Serv Res. 2008:43(1 Pt 1):327-39. https://doi. org/10.1111/j.1475-6773.2007.00745.x.

23. Koo TK, Li MY. A guideline of selecting and reporting Intraclass correlation coefficients for reliability research. J Chiropr Med. 2016 Jun;15(2):155-63. https://doi.org/10.1016/j.jcm.2016.02.012.

24. Dilalla DF. Structural equation modeling: uses and issues. In: Tinsley HEA, Brown SD, editors. Handbook of applied multivariate statistics and mathematical modeling. London: Academic Press; 2000. p. 439-64.

25. Kline RB. Principles and practice of structural equation modeling. New York: The Guilford Press; 2016. p. 188-209.

26. Ayre C, Scally AJ. Critical values for Lawshe's content validity ratio revisiting the original methods of calculation. Meas Eval Couns Dev. 2014:47(1):79-86. https://doi.org/10.1177/0748175613513808.

27. Izquierdo I, Olea J, José AF. Exploratory factor analysis in validation studies: uses and recommendations. Psicothema. 2014;26(3):395-400. https://doi. org/10.7334/psicothema2013.349.

28. Brown TA. Confirmatory factor analysis for applied research. New York: Guilford Press; 2006.

29. Kristensen MS, Zwisler A-D, Berg SK, et al. Validating the HeartQoL questionnaire in patients with atrial fibrillation. Eur J Prev Cardiol. 2016; 23(14):1496-503.

Ready to submit your research? Choose BMC and benefit from:

- fast, convenient online submission

- thorough peer review by experienced researchers in your field

- rapid publication on acceptance

- support for research data, including large and complex data types

- gold Open Access which fosters wider collaboration and increased citations

- maximum visibility for your research: over $100 \mathrm{M}$ website views per year

At BMC, research is always in progress.

Learn more biomedcentral.com/submissions 